\title{
THE JUNE MEETING IN OREGON
}

The two hundred eighty-first regular meeting of the Society was held at the University of Oregon, Eugene, Oregon, on the morning of Friday, June 20, 1930. The meeting was called to order by President Hedrick, who was relieved during the session by Professors E. T. Bell, H. F. Blichfeldt, and R. E. Moritz. Professor E. E. DeCou was elected as acting Secretary in the absence of Associate Secretary T. M. Putnam.

The attendance included the following seventeen members:

E. B. Beauty, E. T. Bell, John Biggerstaff, H. F. Blichfeldt, Daniel Buchanan, L. G. Butler, J. W. Campbell, D. R. Davis, E. E. DeCou, F. L. Griffin, E. R. Hedrick, L. H. McFarlan, R. E. Moritz, J. M. Rankin, J. V. Uspensky, J. R. Vatnsdal, R. M. Winger.

A business meeting was held at the close of the morning session in which the following changes in the By-Laws were adopted as recommended by the Council of the Society at the April meeting.

(a) The first sentence of Article 10, Section 1, to read as follows:

The Society shall publish an official organ called the Bulletin of the American Mathematical Society which shall be sent to each member of the Society; five dollars of the dues paid by each member shall be for a year's subscription to this publication.

(b) The period at the end of the first sentence of Article 6, Section 2, to be replaced by a semi-colon (;) and to be followed by:

Five dollars of the dues of each member shall be for a year's subscription to the Bulletin.

It was voted to recommend to the Council that a meeting be held in June, 1931, at the University of Washington, it being understood that there will be a meeting at Thanksgiving at the University of California at Los Angeles, and a meeting in April at the University of California at Berkeley.

A luncheon for members and guests was provided at the dining-room of the University of Oregon, after which there were 
automobile trips to the mountains and to the Oregon State College.

The titles of papers read at the meeting follow. Those whose abstract numbers are followed by the letter $t$ were read by title. Mr. Small and Miss Swanson were introduced by Professor Griffin. The paper of Professor Milne was read by Professor DeCou.

1. Residues of certain binomial coefficients for composite moduli, by Professor E. T. Bell. (Abstract No. 36-5-278-t.)

2. Unique decomposition, by Professor E. T. Bell. (Abstract No. 36-5-279-t.)

3. Rings whose elements are ideals, by Professor E. T. Bell. (Abstract No. 36-5-280.)

4. A theory of certain fields of points, by Professor E. T. Bell. (Abstract No. 36-5-281-t.)

5. An extension of the Alexander duality theorem, by $\mathrm{Dr}$. A. B. Brown. (Abstract No. 36-5-282-t.)

6. Periodic orbits in the problem of three bodies with repulsive and attractive forces, by Professor Daniel Buchanan. (Abstract No. 36-5-283.)

7. Periodic orbits in the problem of four bodies with repulsive and attractive forces, by Professor Daniel Buchanan. (Abstract No. 36-5-284.)

8. The word "logarithm" used before the time of Napier, by Professor Florian Cajori. (Abstract No. 36-5-285-t.)

9. The cellular division and approximation of regular spreads, by Dr. S. S. Cairns. (Abstract No. 36-7-290-t.)

10. Note on ruled surfaces and their developables, by Professor A. F. Carpenter. (Abstract No. 36-5-286.)

11. On minimizing certain types of definite integrals, by Professor D. R. Davis. (Abstract No. 36-7-291.)

12. The expansion of analytic functions in the form $b_{0}$ $+\sum_{1}^{\infty} b_{n} a_{n} z_{n} /\left(1-a_{n} z^{n}\right)$, by Dr. J. M. Feld. (Abstract No. 36-7292-t.)

13. Mutual inpedances of grounded circuits, by Mr. R. M. Foster. (Abstract No. 36-5-287-t.) 
14. An application of a theorem of Junker, by Professor Raymond Garver. (Abstract No. 36-5-288-t.)

15. Varieties of polar singularities of non-analytic functions, by Professor E. R. Hedrick. (Abstract No. 36-5-289-t.)

16. Linear functional equations in the composite range of a function and $n$ independent variables, by Mr. L. S. Kennison. (Abstrat No. 36-7-293-t.)

17. The problem of Lagrange of the calculus of variations for which the integrand contains the coordinates of the end points, by Professor L. H. McFarlan. (Abstract No. 36-7-294.)

18. Quadratic functional forms in a composite range, by Professor A. D. Michal and Mr. L. S. Kennison. (Abstract No. 36-7-295-t.)

19. On the maximum absolute value of the derivative of $e^{-x^{2}} P_{n}(x)$, by Professor W. E. Milne. (Abstract No. 36-7-296.)

20. On doubly-depleted Fourier's of the types $\sum_{1}^{\infty} f(n) \cos (n x)$ and $\sum_{1}^{\infty} f(n)$ sin $(n x)$, where $f(n)$ is a homogeneous function of $n$, by Professor R. E. Moritz. (Abstract No. 36-7-297.)

21. A center-surface for the ellipsoid, by Mr. J. B. Small. (Abstract No. 36-7-298.)

22. Curved wires of minimum attraction for a given particle, by Miss Florence E. Swanson. (Abstract No. 36-7-299.)

23. On the determination of stringing tensions for transmission lines and cables, by Professor J. W. Campbell. (Abstract No. 36-7-300.)

24. Incomplete numerical functions, by Professor J. V. Uspensky. (Abstract No. 36-7-301.)

25. Ch. Jordan's series for probability, by Professor J. V. Uspensky. (Abstract No. 36-7-302-t.)

T. M. Putnam, Associate Secretary 